\title{
A cross-sectional study of dentists about the need for a practice management course in undergraduate dental program
}

\author{
Muhammad Ashraf Nazir ${ }^{1}$, Faisal Izhar ${ }^{2}$, Kalsoom Tariq ${ }^{2}$, Khalid Mehmood Anjum ${ }^{3}$, \\ Zaid Bin Sohail ${ }^{3}$, Khalid Almas ${ }^{1}$
}

Correspondence: Dr. Muhammad Ashraf Nazir Email: manazir@uod.edu.sa

\begin{abstract}
'Department of Preventive Dental Sciences, College of Dentistry, Imam Abdulrahman Bin Faisal University, Dammam, Saudi Arabia,

2Department of Community and Preventive Dentistry, College of Dentistry, FMH College of Medicine and Dentistry, Lahore, Pakistan,

${ }^{3}$ College of Dentistry, FMH College of Medicine and Dentistry, Lahore, Pakistan
\end{abstract}

\section{ABSTRACT}

Objective: To evaluate dentists' opinions about the need for a practice management course in the undergraduate dental program. Materials and Methods: This cross-sectional study was conducted in 2017 on practicing dentists in Lahore, Pakistan. A self-administered pilot-tested questionnaire was distributed among 588 dentists using a convenience sampling method to obtain their responses about the need for a practice management course. Descriptive statistics and bivariate and multivariate logistic regression analyses were performed. Results: About $83.8 \%$ of 588 dentists completed the questionnaires. There were $36.7 \%$ of males and $63.3 \%$ of females (mean age $26.22 \pm 4.8$ years). The principles of patient management (94.1\%), time management skills $(90.3 \%)$, and teamwork $(89.2 \%)$ were the most commonly agreed topics of the practice management course. The least agreed topics included office design $(59.2 \%)$, health-care systems $(60.9 \%)$, and inventory systems (69\%). Most participants (74.4\%) thought that a practice management course is required to successfully manage a dental practice, and $63 \%$ recommended to include the course in the dental curriculum. Multivariate logistic regression showed that dentists working in private clinic (odds ratio $(\mathrm{OR}): 3.35, P=0.001$ ), dentists with graduation within $\leq$ past 5 years (OR: 3.64, $P=0.001)$, and dentists who attended a practice management course (OR: $3.12, P=0.001)$ were more likely to agree to the need of a practice management course to successfully run a dental office. Conclusion: Most dentists believed that a practice management course is required for a successful dental practice. The development and implementation of such a course should be based on the feedback from dentists to ensure evidence-based approaches.

Key words: Dental practice, dentists, practice management

\section{INTRODUCTION}

Technological advances, the emergence of new knowledge, greater expectations of patients about standards of dental care, and economic factors

\begin{tabular}{|l|l|}
\hline \multicolumn{2}{|c|}{ Access this article online } \\
\hline Quick Response Code: \\
\hline
\end{tabular}

This is an open access journal, and articles are distributed under the terms of the Creative Commons Attribution-NonCommercial-ShareAlike 4.0 License, which allows others to remix, tweak, and build upon the work non-commercially, as long as appropriate credit is given and the new creations are licensed under the identical terms.

For reprints contact: reprints@medknow.com

How to cite this article: Nazir MA, Izhar F, Tariq K, Anjum KM, Sohail ZB, Almas K. A cross-sectional study of dentists about the need for a practice management course in undergraduate dental program. Eur J Dent 2018;12:508-15.

DOI: 10.4103/ejd.ejd_184_18 
are bringing challenges to a dental profession which require producing future dentists with the knowledge of management and leadership through improved curriculum. ${ }^{[1]}$ The Commission on Dental Accreditation requires dental students to acquire knowledge and skills of dental practice management to become a successful leader of the dental team. ${ }^{[2]}$ Leadership training can be provided by teaching communication skills, staff management, patient management, teamwork, conflict management, and financial resource management through a practice management course ${ }^{[3]}$ However, dental curricula lack the content that emphasizes the principles of practice administration and effective management of patients, and a large body of evidence reports that students feel not well prepared to run a private dental practice, particularly at the start of their careers. ${ }^{[4-8]}$

The literature reports the challenges encountered by the dentists at the beginning of their professional journey. In the US, a survey found that practicing general dentists had less knowledge about the business aspect of dental practice, human resource management, dental insurance, and legal aspect of dentistry. They improved these skills over the years during dental practice, hence stressing the need to improve such deficiencies in dental curriculum. ${ }^{[9]}$ In France, undergraduate students pointed out time management and handling of administrative tasks as the main challenges at the start of their career. ${ }^{[10]}$ More than half of dentists in the Netherland reported that they were not prepared for the management of dental staff, the organization of practice, legal aspects of dentistry, and matters related to dental insurance. ${ }^{[11]}$ Similarly, dental practitioners were concerned about managing financial and legal matters, understanding dental market and culture, and dealing with occupational health problems in Mexico. ${ }^{[12]}$ The inclusion of topics related to business and practice management in a new dental program was most commonly recommended by the dentists in the U.K. ${ }^{[13]}$ Senior Malaysian dentists stressed the need to pay attention to improve the knowledge and skills of principles of management, staff administration, and professional developments among graduating students. ${ }^{[14]}$ In Iran, 70\% of general dentists were highly satisfied with a practice management course, and $87 \%$ expressed the need for more such training courses. ${ }^{[15]}$

In the US, the successful management of dental practice is crucial for dentists as $85 \%$ of graduating dentists plan to start a private dental practice upon their graduation. ${ }^{[4]}$ As of February 2018, there were 19,539 general dentists registered with Pakistan Medical and Dental Council, a statutory body that regulates physicians and dentists in Pakistan. ${ }^{[16]}$ Many dental graduates work in private or government sector in the country and others pursue a career abroad. Regardless of the type of career path, a graduating dentist would benefit from a leadership course. However, the current undergraduate dental curriculum lacks a practice management course that should include topics related to the concepts of management and leadership, financial management, marketing of dental practice, appointment, and record management systems to name a few. It is important to seek the opinions of practicing dentists and dental faculty members to align a practice administration course with the current trends and demands of dental practice. Therefore, this study aimed to evaluate the responses of dental professionals about the need for a practice management course.

\section{MATERIALS AND METHODS}

The cross-sectional study included practicing general dentists in Lahore, Pakistan. A sample size $(n=588)$ was calculated using 95\% confidence limit, anticipated percentage frequency, and population size of the participants. ${ }^{[17]}$ A self-administered questionnaire was used for data collection. A comprehensive review of syllabi of different practice management courses in international dental schools was carried out. Practice management courses/syllabi were searched in America, Canada, Australia, United Kingdom, India, and Pakistan. The syllabi were retrieved from the websites of different dental colleges and dental regulatory/statutory bodies in these countries. The retrieval and review process of the syllabi spanned over about 3 weeks. Practice management/administration courses differ in their methods of delivery, content, assessment, year of the dental program, the degree of involvement of instructors, and guest speakers. Further, a literature review of previous studies was conducted to evaluate different topics related to practice management course. ${ }^{[6-12,14,15,18]}$

The questionnaire was developed based on the review of 17 courses/syllabi and previous studies in addition to keeping the growing needs of the dental profession in Pakistan. It contained items related to financial resources, record management, appointment management system, inventory systems, teamwork, marketing, principles of designs of dental practice, use of information technology, development 
of business plan, and understanding of the concepts of quality assurance, accreditation, and management and leadership skills. The instrument broadly inquired respondents about their demographic and background information (age, gender, type of job, year since graduation, basic dental qualification obtained from private and public institute, and attendance of a practice management course), the inclusion of topics in the practice management course, and the need for such a course in the undergraduate dentistry programs in the country. In addition, the respondents were asked about the most effective methods of delivery of the course. The study participants were also requested to provide their opinion about the sectors that provide lucrative career opportunities (public and private jobs, and employment in academia and companies dealing in dentistry) for graduating dentists in the country. Five-points Likert scale (strongly disagree, disagree, neutral, agree, and strongly agree) was used to evaluate participants' responses about the content of the course.

The initial draft of the questionnaire was developed and discussed among the authors. The suggestions about rephrasing some questions were incorporated in the next version of the questionnaire. These measures ensured the questionnaire's content and face validity. ${ }^{[19]}$ Pilot-testing of the questionnaire was also carried out among 30 participants. The process improves the quality of the questionnaire by deleting and retaining individual items, enhances the understanding of questions by the respondents and helps to evaluate the time needed to fill out the questionnaire. ${ }^{[20]} \mathrm{A}$ Cronbach alpha of the items related to the topics of practice management was calculated and found excellent (0.97). The final draft of the self-administered questionnaire was distributed in person among 588 study participants in different dental colleges and private and public clinics. A convenience sampling method was used to obtain the responses of general practitioners. The research assistants collected data from August 2017 to November 2017. Maximum three visits were made to achieve a high response rate of general dentists. Each consecutive visit was performed after 2-3 weeks duration.

The study was approved by the Institutional Review Board of the FMJ Medical and Dental College, Lahore. The information about the study including its purpose and objectives were provided to the study participants, and they were informed about their voluntary participation in the study. Moreover, respondents' privacy and confidentiality were maintained by filling out an anonymous questionnaire. Informed consent was obtained.

Statistical analysis was carried out using SPSS software (IBM SPSS Statistics for Windows, Version 22.0. Armonk, NY: IBM Corp). Frequency distribution of participants' responses, means, and standard deviations of quantitative variables was calculated. Chi-square tests allowed the comparisons of individual items responses between male and female dentists. Bivariate and multivariate logistic regression analyses were used to evaluate the influence of independent variables (gender, type of clinic, years since graduation, monthly earnings, etc.) on the dependent variables (need of the course for successful practice management and the inclusion of topics in the course) of the study. For statistical tests, the $P$ value was set at $<0.05$.

\section{RESULTS}

The response rate was $83.8 \%$ (493 of 588 dentists completed the questionnaires). Mean age of the participants was $26.22 \pm 4.8$ years. There were $36.7 \%$ of males and $63.3 \%$ of females in the study. Most participants received basic dental qualification from private dental institutions $(86.6 \%)$, earned $<500 \$$ U. S per month $(74.8 \%)$, graduated within $\leq$ past 5 years $(69 \%)$, and worked in private dental clinics $(82.6 \%)$. A small percentage $(16.6 \%)$ attended a practice management course [Table 1].

\begin{tabular}{lc}
\multicolumn{2}{l}{ Table 1: Demographic characteristics of the study } \\
participants $(\boldsymbol{n}=\mathbf{4 9 3})$ in Lahore, Pakistan \\
\hline Variables & $\boldsymbol{n}(\%)$ \\
\hline Gender & $181(36.7)$ \\
$\quad$ Male & $312(63.3)$ \\
$\quad$ Female & \\
Type of job & $407(82.6)$ \\
$\quad$ Private & $86(17.4)$ \\
Public & \\
Basic dental qualification obtained from & $427(86.6)$ \\
$\quad$ Private institution & $66(13.4)$ \\
Public institution & \\
Year since graduation (years) & $340(69.0)$ \\
$\quad \leq 5$ & $153(31.0)$ \\
$\quad>5$ & \\
Income monthly (\$ US) & $369(74.8)$ \\
$\quad<500$ & $124(25.2)$ \\
$\geq 500$ & $82(16.6)$ \\
Attended a practice management course & $26.22 \pm 4.8$ \\
Age, mean $\pm S D$ & \\
\hline SD: Standard deviation &
\end{tabular}


The participants' responses regarding the content of a practice management course are presented in Table 2. The agreed and strongly agreed options were combined to give agreed responses. Most participants agreed that "principles of patient management" (94.1\%), "time management skills" (90.3\%), and "teamwork" (89.2\%) should be included in a practice management course. The "factors affecting office design" (59.2\%), "healthcare systems in some Western countries" (60.9\%), and "principles of inventory systems" (69\%) were three least agreed on items that should be incorporated in the course.

The gender differences between dentists' responses about the inclusion of topics were investigated. It was found that significantly higher proportions of female dentists compared with male dentists agreed that "patient management" $(P<0.001)$, "dental staff management" $(P<0.001)$, "time management skills" $(P<0.001)$, and "marketing in dentistry" $(P<0.001)$ and other topics should be included in the course. Overall, more females than males agreed to include most topics in a practice management course. Most participants (74.4\%) agreed that a practice management course is required to successfully manage private and public dental clinic and $63 \%$ believed that practice management course should be included in the undergraduate dental curriculum.

Bivariate and multivariate logistic regression analyses were performed to evaluate the influence of independent variables of the study on participants'

\begin{tabular}{|c|c|c|c|c|}
\hline Response & Agree, $n(\%)$ & Male, $n(\%)$ & Females, $n(\%)$ & $P$ \\
\hline $\begin{array}{l}\text { "General concepts of management and leadership" } \\
\text { should be included in the course }\end{array}$ & $421(85.4)$ & $149(35.4)$ & $272(64.6)$ & 0.141 \\
\hline "Principles of patient management" should be discussed in the course & $464(94.1)$ & $160(34.5)$ & $304(65.5)$ & $<0.001$ \\
\hline "Principles of dental staff management" should be included in the course & $436(88.4)$ & $149(34.2)$ & $287(65.8)$ & $<0.001$ \\
\hline "Conflicts management" should be taught in the course & $405(82.2)$ & $143(35.3)$ & $262(64.7)$ & 0.165 \\
\hline "Importance of Teamwork" should be discussed in the course & $440(89.2)$ & $164(37.3)$ & $276(62.7)$ & 0.458 \\
\hline "Time management skills" should be included in the course & $445(90.3)$ & $151(33.9)$ & $294(66.1)$ & $<0.001$ \\
\hline $\begin{array}{l}\text { Students should be trained in "Verbal and written } \\
\text { communication skills" in the course }\end{array}$ & $434(88)$ & $160(36.9)$ & $274(63.1)$ & 0.849 \\
\hline $\begin{array}{l}\text { Knowledge about "Health Care Systems in Pakistan" } \\
\text { should be discussed in the course }\end{array}$ & $415(84.2)$ & $152(36.6)$ & $263(63.4)$ & 0.926 \\
\hline $\begin{array}{l}\text { Knowledge about "Health Care Systems in some Western } \\
\text { countries" should be taught in the course }\end{array}$ & $300(60.9)$ & $110(36.7)$ & $190(63.3)$ & 0.978 \\
\hline $\begin{array}{l}\text { Knowledge about "the regulatory requirements to establish a private } \\
\text { dental office/clinic in Pakistan" should be included in the course }\end{array}$ & $389(78.9)$ & $142(36.5)$ & $247(63.5)$ & 0.851 \\
\hline $\begin{array}{l}\text { "Employability skills (job search, resume writing and } \\
\text { interviewing)" should be taught in the course }\end{array}$ & $426(86.4)$ & $154(36.2)$ & $272(63.8)$ & 0.513 \\
\hline "Factors affecting office design" should be included in the course & $292(59.2)$ & $111(38)$ & $181(62)$ & 0.471 \\
\hline $\begin{array}{l}\text { "Principles of records management system" } \\
\text { should be included in the course }\end{array}$ & $354(71.8)$ & $130(36.7)$ & $224(63.3)$ & 0.995 \\
\hline $\begin{array}{l}\text { "Principles of appointment management system" } \\
\text { should be described in the course }\end{array}$ & $399(80.9)$ & $156(39.1)$ & $243(60.9)$ & 0.024 \\
\hline "Principles of inventory systems"should be discussed in the course & $340(69)$ & $114(33.5)$ & $226(66.5)$ & 0.029 \\
\hline The students should be familiar with "Use of IT in dental office" & $392(79.5)$ & $134(34.2)$ & $258(65.8)$ & 0.022 \\
\hline $\begin{array}{l}\text { The students should learn "Management of Financial } \\
\text { systems in dental office" in the course }\end{array}$ & $382(77.5)$ & $138(36.1)$ & $244(63.9)$ & 0.615 \\
\hline $\begin{array}{l}\text { "Principles of Quality assurance, control and } \\
\text { improvement" should be discussed in the course }\end{array}$ & $385(78.1)$ & $145(37.7)$ & $240(62.3)$ & 0.41 \\
\hline $\begin{array}{l}\text { Students should learn about "Principles of } \\
\text { accreditation in Dentistry" in the course }\end{array}$ & $358(72.6)$ & $129(36)$ & $229(64)$ & 0.61 \\
\hline $\begin{array}{l}\text { Knowledge about "the current oral health programs and career } \\
\text { opportunities for the graduating dentists in the government } \\
\text { sector in Pakistan" should be included in the course }\end{array}$ & $366(74.2)$ & $121(33.1)$ & $245(66.9)$ & 0.004 \\
\hline $\begin{array}{l}\text { Knowledge about "the Challenges and opportunities for graduating dentists } \\
\text { in the private sector in Pakistan" should be included in the course }\end{array}$ & $358(72.6)$ & $112(31.3)$ & $246(68.7)$ & $<0.001$ \\
\hline Students should learn "Principles of Marketing in Dentistry" in the course & $366(74.2)$ & $150(41)$ & $216(59)$ & $<0.001$ \\
\hline
\end{tabular}


opinion about the need for a practice management course for the successful management of the dental office. Multivariate logistic regression analyses showed that the dentists working in private clinic versus dentists from public clinic (odds ratio (OR): $3.35,95 \%$ confidence interval $(\mathrm{CI}): 1.67,6.73)$, dentists with graduation within $\leq 5$ years versus dentists with $>5$ years since graduation (OR: $3.64,95 \%$ CI: $1.73,7.69)$, and dentists who attended a practice management course versus those who never attended a course (OR: $3.12,95 \%$ CI: 1.61, 6.37) were more likely to agree to the need of a course for the successful management of dental office. On the other hand, the dentists with a monthly salary of $<500$ \$ U. S had lower odds (OR: 0.19, 95\% CI: 0.07, 0.54) of believing in need of a course [Table 3].

The associations between independent variables of the study with participants' opinion about the inclusion of practice management course in the undergraduate dental curriculum were investigated by using bivariate and multivariate logistic regression analyses [Table 4]. Male versus female dentists were 2.31 times more likely to agree to including the practice management course in the dental syllabus (95\% CI: 1.21, 4.42).

The guest speaker presentation $(70.2 \%)$ was the most effective method of delivery of a practice management course. Students' writing assignments (16\%) and presentations (24.3\%) were the least effective teaching methods of the course [Figure 1]. Almost $48 \%$ of the dentists considered private dental practice and a quarter $(23 \%)$ thought a job in government sector as the lucrative careers in dentistry [Figure 2].

\section{DISCUSSION}

Dentists' feedback about the content of a practice management course can be extremely valuable when designing and implementing a course related to dental practice. ${ }^{[15,21]}$ Our study found that such a course can prepare students to successfully run a private clinic and perform in a public clinic. A large majority of the dentists agreed with the inclusion of all the topics in a practice management course. However, the principles of patient management, time management skills, and teamwork were the most commonly agreed topics in the study.

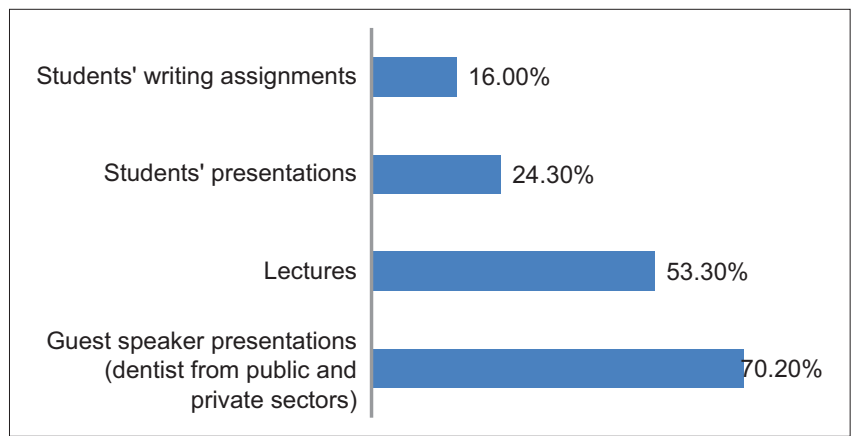

Figure 1: Study participants' opinion $(n=493)$ about the effective modes of delivery of a practice management course in Lahore, Pakistan

\begin{tabular}{|c|c|c|c|c|}
\hline & \multicolumn{4}{|c|}{$\begin{array}{c}\text { The need for a practice management course for the successful management of } \\
\text { dental office }\end{array}$} \\
\hline & Crude OR $(95 \% \mathrm{CI})$ & $P$ & Adjusted OR (95\% Cl) & $P$ \\
\hline $\begin{array}{l}\text { Gender } \\
\text { Male } \\
\text { Female }\end{array}$ & $1.01(0.56-1.82)$ & 0.961 & $0.91(0.47-1.78)$ & 0.792 \\
\hline $\begin{array}{l}\text { Type of job } \\
\text { Private } \\
\text { Public }\end{array}$ & $2.50(1.32-4.74)$ & 0.004 & $3.35(1.67-6.73)$ & 0.001 \\
\hline $\begin{array}{l}\text { Monthly income (\$ US) } \\
\quad<500 \\
\geq 500\end{array}$ & $0.35(0.15-0.85)$ & 0.016 & $0.19(0.07-0.54)$ & 0.002 \\
\hline $\begin{array}{l}\text { Year since graduation (years) } \\
\leq 5 \\
>5\end{array}$ & $1.67(0.93-3.01)$ & 0.085 & $3.64(1.73-7.69)$ & 0.001 \\
\hline $\begin{array}{l}\text { Basic dental qualification (BDS } \\
\text { or equivalent) obtained from } \\
\text { Private dental college } \\
\text { Public dental college }\end{array}$ & $0.51(0.20-1.34)$ & 0.165 & $0.67(0.21-2.13)$ & 0.50 \\
\hline Attended a practice management course & $4.16(2.25-7.72)$ & $<0.0001$ & $3.12(1.61-6.37)$ & 0.001 \\
\hline
\end{tabular}




\begin{tabular}{l} 
Table 4: Results of bivariate and multivariate logistic regression analyses with “inclusion of practice \\
management course in the dental curriculum" by the study participants $(\boldsymbol{n}=493)$ in Lahore, Pakistan \\
\hline \multicolumn{1}{c}{ The inclusion of practice management course in the dental } \\
curriculum
\end{tabular}

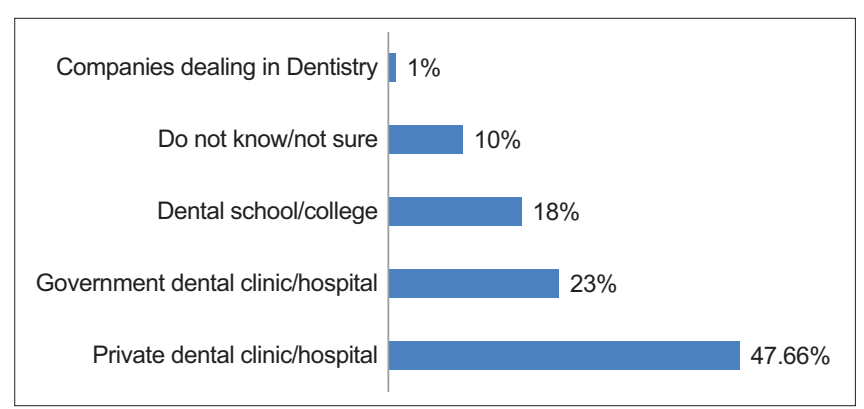

Figure 2: Study participants' opinion $(n=493)$ about the sectors that provide lucrative career opportunities for graduating dentists in Lahore, Pakistan

The success of the dentist is based on the effective management of patients and dental practice. ${ }^{[6]}$ It is also known that increased patient satisfaction is associated with the performance of the dentist. ${ }^{[22]}$ The concept of four-handed dentistry is not new to the dental profession and involves effective teamwork between the dentist and dental team for improved productivity, reduced work-related stresses, and quality of patient care. ${ }^{[23,24]}$ It was reported that four-handed dentistry can result in an increase of $33 \%-75 \%$ in clinical productivity. ${ }^{[24]}$ Efficiency and efficacy of a dental practice can be maximized through effective communication between dentists and dental assistant, dental hygienist, dental receptionists, and dental technicians. Moreover, the teamwork consists of strong collaborations and partnerships between dentists, dental staff, other dentists, specialists, and physicians. Effective patient management, enhanced patient satisfaction, and reduced medical errors can be achieved through teamwork. ${ }^{[25]}$

An efficient appointment system and time management skills go hand in hand in dental practice and ensure clinical productivity and profitability. ${ }^{[26]}$ Time management skills also involve delegating administrative tasks to other members of a dental team. This can allow the dentist provide more time for clinical procedures which can improve the quality of patient care, and enhance patient's confidence in the dentist. ${ }^{[6,27]}$ Therefore, it is of no surprise that a large majority of respondents in our study agreed with the inclusion of topics related to patient management, time management, and teamwork in the course.

On the other hand, a previous study found that the vast majority of dentist recognized the need to educate "medical emergencies" and "ergonomics" as the topics of a practice management course in Iran. ${ }^{[21]}$ In another study, the Iranian dentists gave the highest priority to receiving training in "ergonomics" and "occupational health" in a dental practice management course. ${ }^{[15]} \mathrm{A}$ recent study also emphasized the need for courses in basic life support to reduce the occurrence of medical emergencies in dental practice. ${ }^{[28]}$ Similar to our findings, a previous study of dental residents in the USA reported: "time management" and "multidisciplinary coordination" as the most important topics of practice and patient 
management. ${ }^{[6]}$ In France, a study of final year dental students found that $90 \%$ considered inefficient time management a difficulty at the start of their professional career. ${ }^{[10]}$ Moreover, previous studies have shown that dentists were not prepared for the organization of practice, staff management, financial management, personal development, and handling of legal matters. ${ }^{[11,12,14]}$

Surprisingly, the topics about the factors affecting office design and healthcare systems in some Western countries were least commonly agreed on topics in our study. This suggests that a considerable percentage of the participants lacks the importance of office design and healthcare systems. Nevertheless, dentists in a previous study also gave the lowest priority to workplace design as a topic of practice management course in Iran. ${ }^{[15]}$ Attractive office design can increase patient comfort, enhance the confidence of dental staff and ensure ergonomics. ${ }^{[29]}$ It is assumed that better understanding of healthcare systems of developed countries can provide new ideas and motivations for improving the delivery of health services including oral care services in other countries. This may, in turn, lead to more career opportunities for dental professionals.

The present study showed that a significantly higher percentage of female than male dentists agreed to include most of the topics in a practice management course. In Pakistan, there is an upsurge of dental colleges. ${ }^{[30]}$ More females students are getting admission in dental institutions, and the greater number of graduating female dentists are seeking a career in dental academia, private practice and the public sector. The increased response of female participants in the present study could be because of their greater willingness and participation in dental education and practice. In the present study, most dentists never took a practice management course. This may suggest that there is a lack of continuing education opportunities regarding practice management course available to the practicing dentists in the country.

In our study, most dentists $(74.4 \%)$ believed that a practice management course is required to successfully manage a dental practice. This is in agreement with the results of a previous study where almost two-thirds of participants stated that training in a practice management course is necessary for the successful management of a dental practice. ${ }^{[15]}$ It has been emphasized that knowledge and skills related to practice management should be gained during undergraduate dentistry program and updated continually throughout the career to ensure successful administration of patients and practice. ${ }^{[6,31]}$

The dentists working in a private dental office (OR:3.35), dentists with graduation within $\leq 5$ years (OR: 3.64 ) and dentists who attended a practice management course (OR: 3.12, 95\% CI: 1.61, 6.37) had significantly higher odds of agreeing to the need of a practice management course for a successful dental practice in our study. A greater percentage of graduating dentists were found to enter private practice than pursuing a career in government services. ${ }^{[4]}$ It is possible that dentists who work in private dental clinics run the business of dentistry and their earnings are based on the quantity and quality of dental procedures provided to the patients whereas the dentists in public sector are paid by the government for rendering dental services to the patients. This may place the dentists in private clinics in a better position than the dentist in public sector to provide more positive perspective about running a successful dental practice in our study.

It was reported that the majority of dentists (86\%-89\%) in the U. S. intend to work as a private practitioner after graduation. ${ }^{[4]}$ In Pakistan, it is common that many graduating dentists establish their private dental clinics, while some do so after working for a short period of time as an associate dentist. Within few years, their practices become more profitable and they more efficiently manage patients. Since the successful management of dental practice can occur within few years of start, it is likely that the dentists with graduation $<5$ years might have observed positive practice outcomes which accounted for their more encouraging responses about the course. The attendance of a practice management course can increase dentists' knowledge about different aspects of dental practice. ${ }^{[15]}$ The dentists who previously have attended a course might have noticed the improvement in their practices. This may explain why such dentists had higher odds of acknowledging the role of a practice management course for successfully running a dental clinic.

The collection of data from a large sample of dentists is one of the strengths of the present study as opposed to previous studies that employed around 50 dentists. ${ }^{[15,21]}$ However, our study used a nonprobabilistic convenience sample that may not comprehensively represent the total population of dentists in the city. Therefore, caution should be exercised when generalizing the results of the study. 
In addition, there is a possibility of under and over reporting in a questionnaire-based research.

\section{CONCLUSION}

The study showed that most dentists expressed their agreement about the inclusion of the topics in a practice management course. Most participants believed that a practice management course is required to successfully run a dental practice and agreed to include such a course in the dental curriculum.

It is suggested that the development and implementation of a practice management course should be based on the feedback from practicing dentists to ensure evidence-based approaches in dental education. This will help provide students with the knowledge and skills that are in line with the current trends and demands in the practice of dentistry in public and private sectors. This will prepare our graduating dentists for the successful administration of their dental clinics. Continuing education courses in practice management should also be provided to the practicing dentists.

\section{Financial support and sponsorship}

Nil.

\section{Conflicts of interest}

There are no conflicts of interest.

\section{REFERENCES}

1. Taichman RS, Parkinson JW, Nelson BA, Nordquist B, Ferguson-Young DC, Thompson JF Jr., et al. Leadership training for oral health professionals: A call to action. J Dent Educ 2012;76:185-91.

2. American Dental Association. Commission on Dental Accreditation. Accreditation Standards for Dental Education Programs. Available from: http://www.ada.org/ /media/CODA/Files/predoc.ashx. [Last accessed on 2017 Jun 07].

3. Kalenderian E, Skoulas A, Timothé P, Friedland B. Integrating leadership into a practice management curriculum for dental students. J Dent Educ 2010;74:464-71.

4. Weaver RG, Chmar JE, Haden NK, Valachovic RW. Annual ADEA survey of dental school seniors: 2004 graduating class. J Dent Educ 2005;69:595-619.

5. Gerbert B, Badner V, Maguire B, Martinoff J, Wycoff S, Crawford W, et al. Recent graduates' evaluation of their dental school education. J Dent Educ 1987;51:697-700.

6. Houlberg BJ. Dental residents' perceptions of practice and patient management training during postgraduate education. J Dent Educ 2008;72:643-52.

7. Ralph WJ, Stewart BL, Macmillan CH. Survey of dental practice/dental education in victoria. Part II. Recent graduates/graduating students.
Aust Dent J 1990;35:69-75.

8. Pousson RG, McDonald GT. A model for increasing senior dental student production using private practice principles. J Dent Educ 2004;68:1272-7.

9. Barber M, Wiesen R, Arnold S, Taichman RS, Taichman LS. Perceptions of business skill development by graduates of the university of Michigan dental school. J Dent Educ 2011;75:505-17.

10. Benbelaïd R, Dot D, Levy G, Eid N. Difficulties encountered at the beginning of professional life: Results of a 2003 pilot survey among undergraduate students in Paris Rene Descartes University (France). Eur J Dent Educ 2006;10:204-9.

11. Gorter RC, Storm MK, te Brake JH, Kersten HW, Eijkman MA. Outcome of career expectancies and early professional burnout among newly qualified dentists. Int Dent J 2007;57:279-85.

12. Maupomé G, Borges-Yáñez SA, Dáez-de-Bonilla FJ, Pineda-Cruz A Perceptions of the importance and control of professional problems in the clinical setting. Int J Occup Saf Ergon 2001;7:247-62.

13. Oliver GR, Lynch CD, Chadwick BL, Santini A, Wilson NH. What I wish I'd learned at dental school. Br Dent J 2016;221:187-94.

14. Razak IA, Latifah RR, Jaafar N, Abu Hassan MI, Ab Murat N. Assessing the competency of university of Malaya dental graduates: Employers' and graduates' perceptions. J Dent Educ 2008;72:364-9.

15. Safi Y, Khami MR, Razeghi S, Shamloo N, Soroush M, Akhgari E, et al. Designing and implementation of a course on successful dental practice for dentists. J Dent (Tehran) 2015;12:447-55.

16. Pakistan Medical and Dental Council. Statistics. Available from: http:// www.pmdc.org.pk/Statistics/tabid/103/Default.aspx. [Last accessed on 2018 Mar 07].

17. Sullivan KM, Soe MM. Documentation for Sample Size for a Cross-Sectional, Cohort, or Clinical Trial Studies; 2007. Available from: http://www.openepi.com/PDFDocs/SSCohortDoc.pdf. [Last accessed on $2017 \mathrm{Jul} 23]$.

18. Schonwetter DJ, Schwartz B. Comparing practice management courses in Canadian dental schools. J Dent Educ 2018;82:501-9.

19. DeVon HA, Block ME, Moyle-Wright P, Ernst DM, Hayden SJ, Lazzara DJ, et al. A psychometric toolbox for testing validity and reliability. J Nurs Scholarsh 2007;39:155-64.

20. Rattray J, Jones MC. Essential elements of questionnaire design and development. J Clin Nurs 2007;16:234-43.

21. Khami MR, Akhgari E, Moscowchi A, Yazdani R, Mohebbi SZ, Pakdaman A, et al. Knowledge and attitude of a group of dentists towards the topics of a course on principles of successful dental practice management. J Dent Med 2012;25:41-7.

22. Ali DA. Patient satisfaction in dental healthcare centers. Eur J Dent 2016;10:309-14

23. Finkbeiner BL. Four-handed dentistry: Instrument transfer. J Contemp Dent Pract 2001;2:57-76.

24. Singh N, Jain A, Sinha N, Chauhan A, Rehman R. Application of four-handed dentistry in clinical practice: A review. Int J Dent Med Res 2014;1:8-13.

25. Vandamme K, Opdebeeck H, Naert I. Pathways in multidisciplinary oral health care as a tool to improve clinical performance. Int J Prosthodont 2006;19:227-35.

26. Levin RP. Seven secrets of scheduling. Compend Contin Educ Dent 2004;25:936-7.

27. Levin R. Productive use of office time. J Am Dent Assoc 2005;136:787-8.

28. Al-Shamiri HM, Al-Maweri SA, Shugaa-Addin B, Alaizari NA Hunaish A. Awareness of basic life support among Saudi dental students and interns. Eur J Dent 2017;11:521-5.

29. Finkbeiner BL, Finkbeiner CA. Practice Management for the Dental Team-E-Boo. Missouri, United States: Elsevier Health Sciences; 2015.

30. Pakistan Medical and Dental Council. Recognized Dental Colleges in Pakistan. Available from: http://www.pmdc.org.pk/ RECOGNIZEDDENTALCOLLEGESINPAKISTAN/tabid/167/Default. aspx. [Last accessed on 2017 Dec 14].

31. Nadershahi NA, Nielsen DB. Educating the practice-ready dentist. J Calif Dent Assoc 2005;33:801-4. 